\title{
COMENTARIOS VERTIDOS SOBRE EL LIBRO EL PENSAMIENTO ECONÓMICO DE ARISTÓTELES \\ Isaac Katz*
}

Quiero, antes que otra cosa, agradecer la invitación para estar aquí con ustedes en la presentación del libro El Pensamiento económico de Aristóteles escrito por Scott Meikle.

Todos nosotros somos, en sentido amplio, homo economicus; todos nosotros llevamos a cabo, todos los días, actos que tienen un carácter económico, mismos que se derivan de que todos los agentes económicos, individuos, empresas y gobierno, en cada momento, nos enfrentamos a que contamos con recursos escasos, ingreso y/o tiempo, y por lo tanto, tenemos que elegir qué hacer con ellos, cómo asignarlos entre los varios usos alternativos que existen. No por ello, sin embargo, cualquiera está autorizado para dar opiniones informadas sobre la economía, sustentadas en un riguroso cuerpo de teoría, que busca explicar los fenómenos económicos que observamos todos los días en cualquier país del mundo. Llevar al plano de lo metafísico algo tan mundano como la asignación de recursos y el intercambio, la búsqueda de la satisfacción personal por medio del consumo de bienes, o inclusive decisiones individuales no tan mundanas, pero que no por ello dejan de ser decisiones de carácter económico, como pueden ser la elección de una pareja para contraer matrimonio, el número de hijos que se tienen, cuántos recursos destinamos a su educación y salud, y más, puede llevar a cometer errores de apreciación o inclusive errores que contravienen no solo la teoría económica sino inclusive los fenómenos económicos observables.

* Departamento Académico de Economía, ITAM. 
Estamos aquí reunidos para analizar el pensamiento económico de Aristóteles, filósofo que algunos consideran inclusive como el antecesor de la economía como ciencia, lo que se refleja en que algunos textos sobre la historia del pensamiento económico, como es el caso del libro de Joseph Schumpeter, inician con este autor. Aristóteles vertió sus comentarios sobre esta materia en dos textos: Ética Nicomaquea y Política.

En mis comentarios quiero tocar cuatro puntos alrededor de lo que podría llamarse el pensamiento económico de Aristóteles: $a$ ) valor de uso y valor de cambio; $b$ ) la concepción de riqueza; $c$ ) el papel del dinero en la economía; $y, d$ ) equidad en el intercambio e intercambio justo.

\section{Valor de uso y valor de cambio}

Aristóteles, cuya visión perduró hasta entrado el siglo XIX, hace una clara distinción entre valor de uso de un bien y el valor de cambio y, desde su perspectiva, son independientes. "Un zapato fue hecho para usarse, no para venderse". Esta manera de analizar el valor que tiene un bien en la economía, sea para los oferentes o los demandantes, realmente no tiene mucho sentido ya que no es posible separar ambos tipos de "valores". La distinción metafísica carece de sentido.

Un individuo está dispuesto a utilizar un bien porque deriva satisfacción de su utilización pero, dadas ciertas circunstancias, puede optar por venderlo. ¿Bajo qué condiciones lo vendería?; ¿cuál es su precio de reserva? Si en una transacción voluntaria el vendedor del zapato valúa, ex ante, al zapato menos que la valuación que el posible comprador le otorga, la transacción se llevará a cabo y ambos salen ganando: el vendedor obtiene por la venta del bien un flujo de ingreso que le permite adquirir otros bienes, a un precio que cubre su costo de oportunidad, mientras que el comprador obtiene el bien deseado y los recursos utilizados para la adquisición del zapato reflejan, en el margen, su costo de oportunidad. 
Un segundo punto relacionado con el valor. En la filosofía aristotélica, misma que se siguió hasta los economistas clásicos, el valor de un bien se determinaba por la cantidad de trabajo que tenía incluido, lo cual es claramente incorrecto. El valor de un bien, desde la perspectiva de su utilización, es decir el "valor de uso", refleja la valuación que en el margen el individuo le da a su consumo y que determina, en consecuencia, el precio que está dispuesto a pagar por él. Por otra parte, desde una perspectiva del valor de cambio, el precio de un bien no se determina solamente por consideraciones de oferta (el trabajo que fue necesario para hacer el bien), sino que también hay que considerar a la demanda, es decir, lo que los compradores están efectivamente dispuestos a pagar por éste. ${ }^{1}$ De ello podemos concluir que no es posible hacer una separación, meramente artificial, entre valor de uso y valor de cambio. Por ejemplo, ¿cuánto vale una casa a la cual el constructor le dedicó 5,000 horas de trabajo si nadie la quiere comprar, o cuánto vale un libro al cual el autor le tomó innumerables horas escribir si nadie lo desea adquirir? La respuesta es cero, no valen, no importa el valor intrínseco que el arquitecto o el escritor le den a su obra.

Un tercer punto al respecto es la omisión que hace Aristóteles de la relevancia de la calidad que tenga un bien, ya que ello determina, en gran medida, lo que los individuos están dispuestos a pagar y, consecuentemente, determina también los precios relativos. Por ejemplo: un departamento de interés social $=8$ Tsurus; un departamento de interés social $=1$ camioneta Escalade; un departamento de interés social $=0.1$ Ferrari. No tomar en consideración que la calidad importa lleva a cometer errores en el análisis, sobre todo al considerar el valor que los consumidores le otorgan a un bien.

${ }^{1}$ Más adelante se hará un comentario en relación al intercambio equitativo y al intercambio justo. Vale la pena señalar, por ahora, que cuando un intercambio es enteramente voluntario, éste se lleva a cabo porque ambas partes esperan obtener un beneficio del mismo. 


\section{Riqueza}

Un error de Aristóteles (y al parecer también del propio autor del libro que se presenta) es confundir cuatro variables que son totalmente diferentes entre sí: riqueza, ingreso, dinero y crédito. Tratarlos como si fuesen lo mismo lleva a graves errores en el análisis.

Riqueza es un acervo que poseen los individuos y que puede tener o no valor productivo. Así, para un individuo cualquiera su riqueza está constituida por el valor que tengan en el mercado todos aquellos bienes que posee: su casa, los muebles dentro de su casa, su automóvil, su ropa, sus activos financieros, incluida la tenencia de dinero, el capital de su empresa y, muy importante, su capital humano. Para el individuo, la utilización productiva de parte de su riqueza le permite generar un flujo de ingreso que, a su vez, le permite adquirir aquellos bienes con los cuales va a satisfacer sus necesidades y las de su familia. Además, para aquella parte de la riqueza que no tiene como tal un valor productivo, siempre se puede asignar un valor imputado de ingreso, mismo que mediría el costo de oportunidad de tener un determinado activo en lugar de arrendarlo, como por ejemplo sería el caso de una casa.

Al nivel agregado, es decir, para la economía en su conjunto, la riqueza se mide como el acervo de capital, físico y humano, que permite, con su utilización productiva, generar un flujo de ingreso para los poseedores de este acervo. Con lo anterior, queda claro que riqueza e ingreso no son lo mismo. El primero es un acervo y el segundo un flujo que se deriva de la utilización productiva del primero.

Por otra parte, el dinero es un acervo y forma parte de la riqueza del individuo; no es toda la riqueza y menos aún es ingreso. El que una economía esté monetizada y todas las magnitudes (riqueza, ingreso, precios, crédito, etcétera) se expresen en términos del numerario que se esté utilizando, no hace que el ingreso sea igual a dinero; fácilmente podría expresarse el ingreso percibido en términos de cualquier bien: ¿Cuánto ganas?, 10,000 pesos mensuales o 2 barriles de petróleo.

Crédito tampoco es lo mismo que dinero. Crédito es, para quien lo otorga, un activo, y para quien lo recibe, un pasivo. Para quien lo otorga, es el sacrificio que está dispuesto a hacer de consumo presente y pospo- 
nerlo hacia el futuro, mientras quien los recibe, lo utiliza ya sea para invertir o para adelantar al presente consumo, a costa de sacrificar consumo en el futuro. Para que el prestamista y el prestatario lleven a cabo una operación de crédito, tienen que estar de acuerdo en los términos bajo los cuales se llevará a cabo la operación, particularmente en cuanto a tres variables: tasa de interés, plazo y términos de repago, punto que se tratará más adelante con mayor detalle.

\section{Dinero}

Aristóteles señala correctamente que el dinero facilita las transacciones en una economía; donde comete un error es al afirmar que el dinero es lo que hace conmensurables dos bienes que son intrínsicamente diferentes. Siempre es posible establecer cuántas unidades de un bien equivalen a una unidad de cualquier otro bien si hay dinero de por medio. El dinero, al ser la unidad de cuenta de una economía, el numerario del sistema, así como el medio de pago generalmente aceptado, sólo facilita las transacciones. El dinero reduce los costos de transacción en la economía al facilitar para todo aquél que se involucra en una transacción, establecer los precios relativos, es decir, los términos del intercambio. ${ }^{2}$ Sin dinero, los costos de transacción y de información, a medida que el número de bienes aumenta, aumentan exponencialmente, lo que haría prácticamente imposible el funcionamiento eficiente de la economía ya que no habría manera de que los individuos supiesen todos los términos de intercambio. ${ }^{3}$

${ }^{2}$ A medida que aumenta el número de bienes en la economía, el número de precios relativos, que mide los términos de intercambio, aumentan exponencialmente. Así, con dos bienes hay un solo precio relativo; con tres bienes el número de precios relativos aumenta a tres; cuando hay diez bienes, el número de precios relativos es de 45; con mil bienes existentes, el número de precios relativos aumenta a 499,500.

${ }^{3}$ Más aún, e independientemente del número de bienes, si en una economía no existe el dinero, para que se lleve a cabo cualquier transacción tiene que haber, necesariamente, la doble coincidencia de deseos: primero, dos individuos tienen que estar de acuerdo en qué bienes van a intercambiar; $y$, segundo, tienen que ponerse de acuerdo en los términos del intercambio, es 
En donde Aristóteles se equivoca, en mi opinión, es cuando critica la cadena dinero-bienes-dinero, y más aún, cuando no solamente la critica, sino inclusive condena la cadena dinero-dinero (derivado de las operaciones crediticias). Él acepta la cadena bienes-bienes como algo moralmente válido y, en menor grado, acepta la cadena bienesdinero-bienes, en donde el dinero es simplemente el medio de pago que facilita la transacción.

Partimos del hecho de que la cantidad de dinero que un individuo posee forma parte de su riqueza, pero los individuos no demandan dinero por el dinero en sí mismo. No estamos hablando del Rey Midas ni tampoco, discusión inútil, de cómo sería la moralidad o inmoralidad de Rico Mc Pato, que obtiene satisfacción echándose clavados en su arca llena de dinero.

Los individuos demandan dinero, están dispuestos a mantener parte de su riqueza en forma de dinero, por los servicios que provee el dinero y no por el dinero en sí mismo. Destacan entre los servicios que provee el dinero:

a) servir como medio de pago (evita que las transacciones se lleven a cabo mediante el trueque);

b) ser el numerario del sistema (facilita conocer los precios relativos);

c) separar, en el tiempo, las decisiones de ingreso de las decisiones de gasto (Aristóteles así lo señala); y,

d) servir como almacén de valor (mantener en dinero parte de la riqueza).

Aristóteles condena la moralidad de aquellos que acumulan dinero porque confunde dinero con riqueza. Pero condena aun más la "mala acumulación de riqueza", la "crematística artificial" (tener más riqueza de la que necesito para satisfacer mis necesidades básicas, como si se pudiese establecer cuáles son básicas y cuáles no para cada uno de los

decir, ponerse de acuerdo en los precios relativos. Si esta doble coincidencia no se presenta, la transacción no se lleva a cabo. Adicionalmente, cuando las transacciones se llevan a cabo mediante el trueque, existe el problema de que los diferentes bienes no son perfectamente divisibles; esta indivisibilidad obviamente incrementa los costos de transacción y puede llevar inclusive a que sea imposible concretar la transacción. 
individuos). Aristóteles condena, particularmente, aquella riqueza que se deriva de las operaciones comerciales (la cadena dinero-bienes-dinero) y, más todavía, la que se deriva de las operaciones de crédito, la denominada usura en la tradición escolástica de la Iglesia católica.

La crematística artificial es inconsistente con el hecho de que los individuos siempre prefieren más que menos de todo aquello que les deriva satisfacción. Además, dado que los individuos no acumulan riqueza por la riqueza en sí misma, sino por que les permite, con el ingreso que genera esa riqueza, adquirir una mayor cantidad de satisfactores, el que Aristóteles critique la crematística artificial es inconsistente con su aceptación del dinero como un medio para desligar en el tiempo las decisiones de ingreso de las de gasto.

Y además, vale la pena preguntarse, ¿es inmoral acumular riqueza cuando el individuo destina sus recursos a actividades lícitas en mercados competitivos?

En cuanto al crédito, duramente criticado por Aristóteles, es nuevamente el resultado de la confusión entre riqueza y dinero. Cuando un individuo ahorra, lo que está haciendo efectivamente es otorgar un crédito a alguien que en el presente está des-ahorrando. Para el individuo que ahorra parte de su ingreso, ahorro que se canaliza a otros agentes económicos mediante el crédito, dado que prefiere el presente, es decir, los individuos son ansiosos (particularmente porque no saben cuándo se van a morir), reducir el consumo en el presente conlleva un sacrificio, hay un costo de oportunidad; por lo mismo, para compensar este sacrificio es que se exige una tasa de interés sobre su ahorro, tasa que está dispuesto a pagar el que recibe el crédito para poder consumir en el presente por arriba de su ingreso, o inclusive destinar los recursos obtenidos mediante el crédito para financiar una acumulación de capital. Estas operaciones de ahorro-crédito bajo ninguna circunstancia son usura, y haberla condenado, al igual que la condena sobre acumulación de riqueza que fue adoptada posteriormente por la Iglesia Católica, condenó por muchos siglos a una parte de la humanidad a la pobreza y el subdesarrollo. Tan es así que todavía en gran parte de los países en los cuales predomina la población católica ser rico sigue siendo mal visto. 


\section{Intercambio}

Por último, el tema que es central al pensamiento económico de Aristóteles: el intercambio justo.

Los individuos tienen diversas necesidades que satisfacer y, simultáneamente, poseen recursos productivos escasos. Está en el interés de cada uno de los individuos especializarse en aquella actividad en la cual poseen ventajas comparativas e involucrarse en operaciones de intercambio. Cuando las transacciones son voluntarias, ambas partes ganan, ambos obtienen un beneficio.

No se puede hablar de intercambio equitativo y menos aún de intercambio justo. Intercambio equitativo implicaría que ambos se benefician por igual, lo cual no es cierto. No es lo mismo intercambio equitativo que ponerse de acuerdo sobre los términos del intercambio, como lo hace Aristóteles.

El intercambio justo no existe. El precio justo para un demandante es cero, ya que ello lo llevaría al punto de saturación, en donde maximizaría la utilidad total que se deriva del consumo del bien. Para un vendedor, el precio justo es lo más alto posible, tendiendo a infinito. Obviamente, la justicia no es un atributo del intercambio; no se puede hablar de intercambio justo, sino solamente de un intercambio en donde ambas partes se ponen de acuerdo en los precios relativos, en cuántas unidades de un bien equivalen a una unidad del otro bien. Si llegan a un acuerdo, el intercambio se materializa y ambas partes obtienen un beneficio. Las transacciones voluntarias en el mercado son la forma más eficiente de asignación de recursos, nunca de obtener justicia, término que por sí mismo es, por subjetivo, indefinible.

Finalmente, aunque Aristóteles fue de los primeros en adelantar algunos aspectos de carácter económico, no se puede sin embargo afirmar que sea el "padre de la economía", entendiendo ésta como un conjunto ordenado de tesis y de hipótesis que buscan explicar los fenómenos económicos y que pueden ser contrastadas con la realidad. Aristóteles estuvo muy lejos de hacer un análisis científico de la economía. 